\title{
Educação infantil e patrimônio cultural: diálogo entre educadores do Rio de Janeiro e de São Tomé e Príncipe
}

\author{
Cristina Carvalho* \\ Maria Emília Tagliari Santos** \\ Priscila Matos Resinentti*** \\ Rosana Ferreira Alexandre ${ }^{* * * *}$ \\ Thamiris Bastos Lopes ${ }^{* * * *}$
}

\begin{abstract}
Resumo
Quais relações podem ser estabelecidas quando as crianças observam e conhecem as práticas culturais do meio no qual estão inseridas? Buscando refletir sobre questões acerca da formação cultural nas práticas educativas da educação infantil, o artigo discute a construção de outros modos de olhar e valorizar o patrimônio cultural. A partir de um encontro de educadores das ilhas de São Tomé e Príncipe (África) com integrantes do Grupo de Pesquisa em Educação, Museu, Cultura e Infância (GEPEMCI/PUC-Rio) é proposta a elucidação dos conceitos de educação, infância e patrimônio cultural com base na análise de inventários culturais participativos.

Palavras-chave: Infância; Práticas educativas; Patrimônio cultural.
\end{abstract}

\section{Early childhood education and cultural heritage: dialogue between Rio de Janeiro and São Tomé and Príncipe educators}

\section{Abstract}

What relationships can be established when children are taken to observe and know the cultural practices of the environment in which they belong? Seeking to reflect questions about cultural education in educational practices of early childhood education, the article discusses the construction of other ways of looking and enhance the cultural heritage. From a meeting of educators of the islands of São Tomé and Príncipe (Africa) with members of a research group on education Grupo de Pesquisa em Educação, Museu, Cultura e Infância (GEPEMCI/PUCRio), it is proposed the theoretical elucidation of the concepts of education, childhood and cultural heritage based on the analysis of participatory cultural inventories.

Key words: Childhood; Educational practices; Cultural heritage.

O Grupo de Pesquisa em Educação, Museu, Cultura e Infância (GEPEMCI/PUC-Rio) investiga a relação da educação com diferentes processos culturais e instâncias de socialização, tematizando práticas e concepções culturais. Atualmente, o objetivo principal do grupo é investigar os setores educativos de museus e centros culturais da cidade do Rio de Janeiro com o intuito de mapear e conhecer as atividades oferecidas às crianças de $0 \mathrm{a}$ 6 anos, a estrutura de funcionamento mantida pelas instituições, os agentes sociais que neles atuam e, principalmente, as estratégias pedagógicas desenvolvidas nesses espaços.

Tendo em vista as discussões e publicações realizadas pelo GEPEMCI e a relevância das temáticas cultura e infância, o Laboratório Interdisciplinar Design e Educação (LIDE/PUCRio) - que tem por princípio básico desenvolver pesquisas que visem potencializar o processo de aquisição de conhecimento por meio de artefatos, ambientes e sistemas analógicos e digitais - nos

*Endereço Eletrônico: cristinacarvalho@puc-rio.br

***Endereço Eletrônico: memiliats@ gmail.com

****Endereço Eletrônico: priscila.resinentti@ gmail.com convidou a ministrar uma atividade denominada "A formação cultural na primeira infância" com educadores do segmento de educação infantil das ilhas de São Tomé e Príncipe (África). O projeto de pesquisa desenvolvido pelo LIDE, no ano de 2015, em parceria com o Ministério de Educação, Cultura e Ciência e o UNICEF teve como objetivo contribuir para a ressignificação do ensino nos Jardins de Infância da República de São Tomé e Príncipe. Nesta perspectiva, a equipe ajudou na elaboração de conteúdo curricular, ofereceu curso de reciclagem para educadores e desenvolveu um projeto de materiais didáticos a ser utilizado nos espaços físicos dos Jardins de Infância desse país africano. A participação do GEPEMCI no projeto de pesquisa consistiu em oferecer aos educadores uma oficina que possibilitasse um repensar sobre suas práticas, buscando a valorização da formação cultural das crianças por meio do patrimônio natural, material e imaterial local. Durante todo o processo de elaboração da atividade, o fato de

${ }^{* * * * * *}$ Endereço Eletrônico: rosanafalexandre@ gmail.com

******Endereço Eletrônico: thamiris_bl @ hotmail.com 
trabalharmos com educadores oriundos de uma realidade tão distinta da vivenciada no Rio de Janeiro foi motivador para compreender melhor as especificidades educacionais e culturais. Ensaiamos um processo de encontrar pontos de conexão e de estranhamento com os modos de vida das ilhas de São Tomé e Príncipe e do Rio de Janeiro, na tentativa de construir uma aproximação com o grupo, entendendo que um diálogo possível partiria da valorização de suas vivências e da concepção de que

Entre os elementos que constituem a cultura de um lugar, alguns podem ser considerados patrimônio cultural. São elementos tão importantes para o grupo que adquirem o valor de um 'bem' - um bem cultural (...) (IPHAN, 2013, p. 5).

A ferramenta que permitiu fazer o levantamento e aprofundar a discussão sobre a relação do patrimônio cultural com o universo educativo infantil foi o inventário participativo ${ }^{1}$. Segundo Kramer (2000), a experiência com a produção cultural contribui na formação de crianças, jovens e adultos, pois pode resgatar trajetórias e relatos, provocar a discussão de valores, crenças e a reflexão crítica da cultura que produzimos e que nos produz, suscita o repensar do sentido da vida, da sociedade contemporânea e, nela, do papel de cada um. Assim, tanto educadores quanto os alunos podem aprender com a cultura e com a arte para que todos tenham acesso aos conhecimentos produzidos, favorecendo a construção da identidade e de valores, além de propiciar a capacidade de narrar as experiências vividas.

\section{Contextos da formação cultural na infância}

Propor uma atividade sobre "A formação cultural na primeira infância" que vislumbrasse o contexto específico dos educadores de duas ilhas africanas foi a força motriz que gerou a reflexão exposta neste artigo. A atividade teve início a partir do desafio de elucidar teoricamente os conceitos de cultura, educação, infância e patrimônio cultural, buscando, assim, um entendimento comum entre educadores de diferentes territórios - Rio de Janeiro e São Tomé e Príncipe - com vivências e práticas distintas.
Primeiramente, trouxemos para o debate o que entendemos por cultura. Além de ser um conceito de difícil definição, existem muitas maneiras de o fazer. Antigamente, a cultura era vista quase como um modo de vida e, atualmente, já se compreende como um processo, justamente por ser o que se partilha, o que há em comum, desde regras, normas, línguas, objetos, além de inúmeros e incontáveis detalhes que compõem uma sociedade em uma época.

A princípio, cultura se relaciona com a produção e a troca de significados - o dar e receber significados - entre os membros de uma sociedade ou o grupo. Dizer que duas pessoas pertencem à mesma cultura, é dizer que elas interpretam o mundo aproximadamente da mesma forma e podem expressar seus pensamentos e sentimentos sobre o mundo de maneiras que serão entre elas compreendidas. Assim a cultura depende da interpretação significativa de seus participantes sobre o que está em torno deles, e o 'fazer sentido' do mundo, de maneira semelhante (Hall, 1997, p. 2).

Para Da Matta (1981), o termo cultura leva a dois entendimentos mais usuais: 1) relacionado à sofisticação, à sabedoria de pessoas/grupos; 2) no campo da antropologia está associado ao modo de vida de uma sociedade, "a maneira de viver total de um grupo, sociedade, país (...)” (p. 2).

É justamente porque compartilham de parcelas importantes deste código (a cultura) que um conjunto de indivíduos com interesses e capacidades distintas e até mesmo opostas, transformam-se num grupo e podem viver juntos sentindo-se parte de uma mesma totalidade ( $\mathrm{Da}$ Matta, 1981, p. 2).

Portanto, pertencer a uma mesma cultura significa entender e reconhecer valores de um determinado grupo em uma época e, esse movimento, acaba por compor uma certa identidade a partir da construção de valores plurais e coletivos.

Interpretando o conceito de cultura definido por Hall (1997) enquanto uma relação entre a produção e a troca de significados entre os membros de uma sociedade ou grupo, e em concordância com o entendimento do termo relacionado à antropologia como trazido por Da Matta (1981), convidamos os educadores de São Tomé e Príncipe a apresentar alguns elementos de sua cultura. Após um exercício 
de aproximações e distanciamentos, em um diálogo cultural entre as ilhas africanas e o Rio de Janeiro, chegamos à reflexão de que a cultura depende da interpretação significativa de seus participantes sobre o que está em torno deles, e o 'fazer sentido' do mundo, de maneira semelhante.

Essa reflexão sobre o conceito de cultura no mundo adulto levou a indagações sobre o conceito de culturas da infância defendido por Corsaro (2007) como culturas produzidas a partir da construção das leituras e representações do mundo geradas na interação entre crianças a partir de jogos, brincadeiras e no uso de suas capacidades expressivas (verbais, gestuais, iconográficas, plásticas etc).

Buscando as contribuições de Benjamin (2015) sobre o entendimento das crianças como parte integrante da sociedade e, como tal, do seu interesse em dialogar com esse público, ressaltamos o quanto as relações afetivas com o lugar podem produzir diversos tipos de conhecimento a partir das interações entre as crianças e o patrimônio cultural do meio em que estão inseridas. Ao discorrer sobre patrimônio cultural, destacamos que este pode ser constituído por formas variadas. Os bens materiais imóveis são associados às estruturas construídas pelo homem, como igrejas, fortes etc, enquanto quadros, coleções de objetos e instrumentos são entendidos como bens culturais móveis. Além dessa subdivisão, apresentamos ainda uma outra concepção, reconhecida como patrimônio cultural imaterial, que diz respeito aos saberes e fazeres de uma determinada comunidade transmitidos entre gerações (IMC, 2011, p. 5-6). Neste último caso, percebe-se que o aspecto mais importante é a partilha realizada pelas pessoas do local sobre o que para elas é relevante, o que as constitui como sujeitos daquele lugar e naquela época. São, portanto, os habitantes de determinado território que possibilitam a existência desse frágil patrimônio.

Nessa perspectiva, foi possível estabelecer pontes com os estudos de Walter Benjamin (1994) acerca da experiência. No ensaio intitulado $\mathrm{O}$ Narrador, o autor retoma a importância desta figura e do ato de contar histórias, pois nessa ação reside a possibilidade de transmissão do conhecimento, ou seja, a experiência em si. Ao ouvir, contar e recontar as histórias, elas vão sendo tecidas e moldadas pelas mãos do próprio narrador, como um artesão que realiza seu trabalho manual.

Ao ressaltar a tradição oral, Benjamin (1994) remete à questão da memória e de como ela é relevante para as histórias. Ao contrário da informação pura, a narrativa não segue um modelo racional, puramente instrutivo e já esclarecido, mas está em aberto e cabe ao ouvinte tecê-la de acordo com seu tempo e lugar.

A narrativa, que durante tanto tempo floresceu num meio de artesão - no campo, no mar e na cidade -, é ela própria, num certo sentido, uma forma artesanal de comunicação. Ela não está interessada em transmitir o 'puro em si' da coisa narrada como uma informação ou um relatório. Ela mergulha a coisa na vida do narrador para em seguida retirá-la dele (BENJAMIN, 1994, p. 205).

Ampliando essa reflexão para as questões relacionadas ao patrimônio, compreendemos que

O patrimônio cultural é um conjunto de bens culturais que estão muito presentes na história do grupo, que foram transmitidos entre várias gerações. Ou seja, são os bens culturais que ligam as pessoas aos seus pais, aos seus avós e àqueles que viveram muito tempo antes delas. São os bens que se quer transmitir às próximas gerações (IPHAN, 2013, p. 5).

Desse modo, em concordância com a abordagem sobre patrimônio cultural imaterial, em que práticas, representações e expressões de uma comunidade são associadas a saberes, técnicas, objetos e lugares (IMC, 2011, p.6), organizamos a atividade com o grupo de educadores de São Tomé e Príncipe. Divididos em grupos, todos foram convidados a fazer uma ficha de levantamento dos bens culturais de sua cidade, também presentes no cotidiano infantil, a partir das seguintes categorias: comidas típicas, festas, lugares, brincadeiras, artesanatos e contos populares. As fichas buscaram investigar as diferentes denominações, descrições, os grupos e as situações no qual estão inseridos, aspectos da conservação e os significados atribuídos a esses bens e faz com que se configurem em referências culturais.

Não por acaso, recorremos à questão da experiência em Benjamin (1994). Foi também com esse intuito que propusemos que os educadores africanos relatassem a relação com o lugar em que vivem, que lembrassem de suas tradições e que as transmitissem às crianças, como forma de valorização, promoção e difusão de seus bens culturais entre as diferentes gerações. Sendo assim, 
a utilização do inventário possibilitou a instauração de um processo de trocas de experiências e memórias entre os educadores africanos, um exercício de rememoração e narrativa conjunta de costumes, brincadeiras, sabores e festas das comunidades as quais pertencem.

Orientadas também pelas contribuições de Vigotski (2009), destacamos o papel docente dos educadores, que em meio à riqueza natural e cultural do país, são sujeitos capazes de ampliar as experiências das crianças com o meio, criando, assim, bases suficientemente sólidas para suas atividades de educação. Nesse sentido, o autor destaca que "quanto mais a criança viu, ouviu e vivenciou, mais ela sabe e assimilou; quanto maior a quantidade de elementos da realidade de que ela dispõe em sua experiência - sendo as demais circunstâncias as mesmas -, mais significativa e produtiva será a atividade de sua imaginação" (VIGOTSKI, 2009, p. 22-23).

\section{Práticas educativas para a infância e a valorização dos patrimônios culturais}

$\begin{array}{ccrr}\text { São } & \text { Tomé } & \text { e } & \begin{array}{c}\text { Príncipe, } \\ \text { oficialmente conhecida }\end{array} \\ \text { como } & \text { República }\end{array}$
Democrática, é composta por duas ilhas principais (Ilha de São Tomé e Ilha do Príncipe) e várias ilhotas ocupando um total de $1001 \mathrm{~km}^{2}$ com cerca de 160 mil habitantes. A ilha não possui fronteiras terrestres e situa-se relativamente próxima das costas do Gabão, Guiné Equatorial, Camarões e Nigéria. É um país de clima equatorial quente e úmido que apresenta uma multiplicidade de microclimas definidos em função da pluviosidade, da temperatura e da localização. Sua história remonta a um passado de colonização portuguesa desde o século XV até sua independência em 1975. Atualmente, a população está distribuída entre as ilhas, onde cerca de $131 \mathrm{mil}$ vivem em São Tomé e seis mil no Príncipe. Descendentes de diferentes grupos étnicos que emigraram para as ilhas desde 1969, estima-se uma população urbana de $64,5 \%$ e população rural de $45,5 \%$.

No ano de 2015, o UNICEF da República de São Tomé e Príncipe, em parceria com o MEC, desenvolveu uma atividade interdisciplinar entre os Departamentos de Design e Educação da Pontifícia Universidade Católica do Rio de Janeiro (PUC-Rio) para a ampliação da formação de seus educadores, visando, assim, ressignificar os espaços dos Jardins de Infância.

Dentre muitas atividades desenvolvidas, o trabalho do GEPEMCI, grupo de pesquisa vinculado ao Programa de Pós-Graduação do Departamento de Educação da PUC-Rio, consistiu em construir junto aos educadores de São Tomé e Príncipe um modo de olhar e valorizar o patrimônio cultural local nas práticas educativas dos Jardins de Infância. A proposta tinha como objetivo o deslocamento do olhar em relação à percepção e valorização do patrimônio cultural do local, uma vez que propomos que a própria comunidade se apropriasse da memória partilhada por todos. Conforme ressaltado anteriormente, após a elucidação teórica dos conceitos supracitados, os educadores foram convidados a inventariar o patrimônio cultural nas seguintes categorias: festas populares, comidas típicas, artesanato, lugares, brincadeiras e contos populares. A seguir, apresentamos alguns dos aspetos destacados pelo grupo:

- Festas Populares: As festas mais populares, como São Lourenço, São Pedro, São João, Santo Antônio, São Izidoro, Deus Pai e Auto Floripes celebram os santos e a cultura da terra. Missas, marchas pelas ruas, encenações e fantasias integram as festividades. Os educadores consideraram que essas festas apresentam vários pontos positivos, pois compõem a cultura tradicional e são comemoradas por todas as comunidades de forma livre e gratuita nas ruas. Tais celebrações representam a possibilidade de retomar a culinária típica, "embora deixem as ruas muito sujas", conforme explicitado por alguns participantes. Consideram que essas festas contribuem também para trazer de volta à comunidade aqueles se afastam por motivos de trabalho, além disso, possibilitam rentabilidade aos moradores.

- Comidas Típicas: Comidas típicas como calulu, izaquecite de azeite/de açúcar, pirão de farinha de mandioca, arroz doce e purê de feijão foram citadas como pratos confeccionados utilizando ingredientes locais - folhas da terra, peixes, óleo de palmeiras, temperos e legumes - frequentemente plantados nas hortas das escolas. De acordo com os educadores, essas iguarias são comuns no cardápio infantil das comunidades santomenses, e os momentos de alimentação das crianças são valorizados na escola, como também nas famílias nos fins de semana e nas festas tradicionais. O plantio da horta é considerado um ponto positivo pelos educadores que alertaram 
para a necessidade de as receitas tradicionais serem seguidas, pois "os ingredientes podem estragar e provocar mal-estar".

- Artesanato: O artesanato local tem como forte tendência a cestaria e os enfeites produzidos com matéria prima do local, como ramos de palmeiras, cascas de coco e sementes. Confeccionados por artesãos da comunidade que trabalham com seu potencial de criação e expressão em barracas embaixo de árvores, em lojas ou ao ar livre. Para os moradores do local, os artesanatos são mais utilizados no cotidiano e não costumam receber a conotação de arte. Ressaltaram ainda que os trabalhos artesanais são mais valorizados pelos turistas.

- Lugares: O Museu Nacional, o Arquivo Histórico, as Cascatas de São Nicolau e Bambaim, o Jardim Botânico, as praias e uma lagoa foram citados como lugares onde se pode encontrar a diversidade biológica e informações históricas do local. Foram considerados pelos educadores como lugares maravilhosos, pontos culturais que podem ser frequentados pelos moradores locais, turistas e passeios escolares. Ressaltaram que esses locais abrigam momentos de leitura, de aquisição de informação, de práticas de jogos de cartas e futebol. Destacaram também que estes são espaços onde se pode conhecer comidas típicas, como peixes, carnes e pães. Os educadores salientaram que falta uma conscientização de preservação da natureza e a disponibilização de locais adequados para o despejo de lixo.

- Brincadeiras: Jogos de semana, jogos de lata, corrida de trote, 1,2,3 macaquinho chinês, malha, dentre outras, foram as brincadeiras citadas como as mais comuns entre as crianças. Para a realização dessas brincadeiras, o uso de cordas e objetos simples foram assinalados pelo grupo de educadores. Relataram que estas são ensinadas pelos mais velhos nas escolas, nas casas, nas ruas da comunidade e nos jardins. Também foi destacado que as brincadeiras aprendidas ainda na infância, mas praticadas em todas as idades, estimulam o desenvolvimento da atenção, da flexibilidade, da memorização e libertam a energia. $\mathrm{O}$ ponto negativo destacado pelo grupo é que "se caírem podem se aleijar" (machucar no nosso vocabulário).

- Contos Populares: A mãe de cabeça grande, pé fim-fim e barriga grande; Alda Espírito Santo; Carlos Bené; Albertino Bragança e João Carlos Silva foram alguns dos contos citados pelo grupo, apresentados como os mais narrados pelos mais velhos para crianças, jovens e adultos nas escolas, nos programas infantis e à noite, nas varandas, em volta da fogueira ou na mesa após o jantar. De acordo com grupos participantes, são contos de lições e de pessoas importantes para a história da comunidade. Os educadores de São Tomé e Príncipe consideram que os contos se configuram como uma forma de incentivar as crianças a gostar de ouvir histórias e aprender sobre personalidades importantes para a comunidade. No entanto, foi relatado que poucas pessoas ainda fazem uso dos contos populares na ilha.

A tentativa dos educadores africanos em deixar os alunos sentindo-se à vontade nas escolas, revelando os seus gostos e tradições, permitiu constatar que o grupo demostrava ter facilidade em lidar com as crianças, desejando a participação delas. De acordo com Dewey (2010),

Do ponto de visto do crescimento como educação e da educação como crescimento, a questão é se o crescimento nessa direção promove ou atrasa o crescimento em geral. (...) qual o efeito do crescimento em uma direção especial sobre as atitudes e hábitos capazes de abrir caminhos para outras direções? (DEWEY, 2010, p. 37).

Ainda, segundo esse mesmo autor,

A concepção ampla de hábitos envolve a formação de atitudes emocionais e intelectuais; envolve nossas sensibilidades básicas e nossos modos de receber e responder a todas as condições com as quais nos deparamos na vida (DEWEY, 2010, p.35).

A partir desse patrimônio cultural inventariado pelos educadores de São Tomé e Príncipe, procuramos incentivá-los a compreender suas práticas como parte de um sistema, reconhecendo a importância do contexto sociocultural no qual os jardins de infância estão inseridos, fazendo-o presente de maneira viva e concreta nas experiências educativas. Assim, os materiais disponíveis nas salas podem ser selecionados e coletados em propostas de investigação do entorno, de identificação da vegetação, de produtos e matérias primas locais etc.

Concordando com Dewey (2010):

Uma responsabilidade fundamental do educador não é apenas estar atento ao princípio geral de 
que as condições ambientais modelam a experiência presente, mas também reconhecer concretamente que as circunstâncias ambientais conduzem a experiências que levam ao crescimento. Acima de tudo, o educador deve saber como utilizar as circunstâncias físicas e sociais existentes, delas extraindo tudo o que possa contribuir para a construção de experiências válidas (DEWEY, 2010, p. 41).

Convidar moradores para contar histórias quase esquecidas e relatar rituais em curso de desaparecimento; buscar trabalhadores locais, como os pescadores, para conversar com as crianças a respeito de suas lidas; observar o artesanato e os adornos presentes nas casas e ver neles conhecimento, soluções inteligentes e inovadoras, e valores estéticos foram propostas de trabalhar a identidade e de pensar o conhecimento de forma mais ampla que surgiram no diálogo com esses educadores. Juntos debatemos sobre como os saberes, as práticas e mesmo os desafios da comunidade podem ser vistos como oportunidades de desencadear processos de aprendizagem, de exploração, de fortalecimento de vínculos sociais, e ainda de empoderamento das crianças e de toda comunidade.

\section{Considerações Finais}

Após a realização da atividade desenvolvida com os educadores de São Tomé e Príncipe, mensurar o que levaram para sua terra natal é algo bem difícil. O retorno que obtivemos, e as marcas deixadas ao entrarmos em contato com os participantes e com o acervo cultural daquele povo também não é mensurável. Mas podemos afirmar que foi uma experiência marcante. Um encontro cultural que precisa ser ainda sedimentado com o tempo ${ }^{2}$, retomando outro sentido do conceito de experiência considerado por Benjamin (1994).

Entretanto, o que observamos, a partir da participação entusiasmada e sempre guiada por muita música, é que incentivamos os educadores de São Tomé e Príncipe a valorizar seu patrimônio natural, material e imaterial - nas práticas educativas de formação cultural na primeira infância. Esse é um esforço que implica na reformulação constante das práticas educativas e que, conforme a dinâmica social, influencia nas mudanças culturais e, consequentemente, no patrimônio cultural da infância de diferentes grupos.
Ainda dialogando com Benjamin (1994), é possível pensar a necessidade de (re)encontrar o homem na sua capacidade de tornar suas experiências comunicáveis, de narrar, de rememorar, de buscar nos fragmentos, na singularidade, simultaneamente, a totalidade tensão que o autor procura resolver essencialmente através da narrativa, da linguagem. Uma linguagem concebida não somente como meio de comunicar o pensamento, mas também como expressão e produção de sentidos. Na perspectiva apontada pelo autor, podemos ampliar a reflexão para a construção de momentos que possibilitem incluir também uma relação diferenciada com nosso patrimônio.

A possibilidade de relatar, partilhar, discutir as narrativas e experiências trazidas por alunos, familiares e professores pode aproximar a relação entre eles e potencializar uma construção coletiva do trabalho por meio da cultura. Segundo Da Matta (1981, p. 4),

O conceito de cultura, ou, a cultura como conceito, então, permite uma perspectiva mais consciente de nós mesmos. Precisamente porque diz que não há homens sem cultura e permite comparar culturas e configurações culturais como entidades iguais, deixando de estabelecer hierarquias em que inevitavelmente existiriam sociedades superiores e inferiores. Mesmo diante de formas culturais aparentemente irracionais, cruéis ou pervertidas, existe o homem a entendê-las - ainda que seja para evitá-las, como fazemos com o crime - é uma tarefa inevitável que faz parte da condição de ser humano e viver num universo marcado e demarcado pela cultura. Em outras palavras, a cultura permite traduzir melhor a diferença entre nós e os outros e, assim fazendo, resgatar a nossa humanidade no outro e a do outro em nós mesmos.

De acordo com Freire (2004), a construção de um saber junto ao educando depende da importância que o educador dá à parte social, à comunidade na qual ele trabalha para conseguir aproximar os contextos à realidade vivida, compondo assim um diálogo aberto com o aluno.

Entendemos que trazer à superfície memórias partilhadas por um grupo significa trazer um pouco de cada um que, em conjunto, constitui o todo. Envolve pensar tanto o que lembrar, quanto o que esquecer. Significa detectar práticas coletivas, vínculos pessoais, assim como as contradições e os conflitos envolvidos. O esforço para lembrar o 
passado da comunidade, é em sua essência um impulso para (re)conhecer o capital cultural daquele grupo. Neste caso, os professores são ao mesmo tempo atores e catalisadores do patrimônio coletivo local. Nesse ponto, é necessário refletir acerca da formação docente. Para que um professor tenha a dimensão do quanto pode contribuir para a formação acadêmica, mas também cultural de seus alunos, tal questão precisa ser contemplada nos cursos de formação inicial e continuada, considerando que os espaços não formais também podem ser locais de formação, mas a escola também pode trazer a cultura do entorno como bem a ser trabalhado, não dependendo apenas de estar localizada próxima a equipamentos culturais.

Carvalho (2005) trabalha o conceito de empobrecimento da experiência, a partir de Benjamin (1994), resgatando a ideia de que o próprio homem não se reconhece mais como sujeito da história, imerso na cultura, criado por ela e, ao mesmo tempo, construtor dessa cultura. Assim, a autora apresenta a discussão de que este empobrecimento ocorre também no processo de formação docente, defendendo que

É preciso pensar alternativas para que futuros professores se percebam como sujeitos construtores de sua prática. A ausência ou a falta de continuidade de políticas de investimento cultural que permitam ao professor, em complementariedade à formação pedagógica, o acesso a bens culturais são dados construídos pelo exercício de uma prática de desvalorização e de descompromisso com uma política social consistente (CARVALHO, 2005, p. 134).

Trabalhar as questões culturais no interior das escolas é pensar a cultura como um direito de todo cidadão, reconhecendo a diversidade cultural e o respeito à mesma, mas também valorizando o patrimônio cultural presente em alunos e professores. $\mathrm{O}$ inventário cultural participativo configura-se como um instrumento que permite viabilizar a construção de uma cidadania cultural em que os diferentes sujeitos da escola percebem-se construtores do saber, e desconstrói a ideia de que é preciso ir aos museus para ter cultura, mas expõe a possibilidade de que o gosto pelos equipamentos culturais pode permitir trocas de conhecimento e a construção da alteridade a partir do reconhecimento de si e de outras formas culturais, possibilitando um diálogo multicultural. Além disso, o uso do inventário coloca uma forte ênfase na vinculação entre o currículo escolar institucionalizado e a experiência que os alunos trazem. Dessa forma, é possível enriquecer a experiência escolar.

Realizar a atividade com as fichas de inventário cultural participativo e arquivar as mesmas pode gerar a preservação da identidade dos diferentes grupos escolares, permitindo, inclusive, a comparação ao longo do tempo, verificando o que se manteve, o que foi modificado. O Patrimônio Cultural Imaterial ou Intangível compreende as expressões de vida e tradições que comunidades, grupos e indivíduos em todas as partes do mundo recebem de seus ancestrais e passam seus conhecimentos a seus descendentes ${ }^{3}$. No entanto, muitas vezes observamos a defesa e a preservação apenas do patrimônio físico, ou seja, de monumentos, lugares históricos e paisagens culturais. Porém, a cultura de um povo não está pautada apenas nos aspectos materiais. Muito de nós está presente nas tradições de um lugar, na dança, no folclore, nas brincadeiras e em outras ações originadas na prática social. Todos esses aspectos são fontes de identidade porque carregam a própria história de um grupo.

\section{Notas}

1 As fichas de inventário distribuídas na atividade foram baseadas no material de Educação Patrimonial publicado pelo IPHAN (2013).

2 Aqui recuperamos como o filósofo Leandro Konder (1999) caracteriza a experiência no sentido benjaminiano.

3 Definição encontrada em: http://www.unesco.org/ new/pt/brasilia/culture/world-heritage/intangibleheritage.

\section{Referências}

BENJAMIN, Walter. Magia e técnica, arte $e$ política: ensaios sobre literatura e história da cultura. Trad. Sergio Paulo Rouanet. São Paulo: Brasiliense, 1994.

A Hora das Crianças - narrativas radiofônicas. Trad. Aldo Medeiros. Rio de Janeiro: Nau Editora, 2015.

CARVALHO, Cristina. Espaços de cultura e formação de professores /monitores. In: LEITE, 
Maria Isabel; OSTETTO, Luciana E. (Org.) Museu, educação e cultura: encontros de crianças e professores com a arte. Campinas: Papirus, 2005.

CORSARO, William. Reprodução Interpretativa e Cultura de Pares em Crianças. Indiana University, Bloomington, 2005. Tradução: Ana Carvalho. Disponível em: $\langle$ http://www.cedes.unicamp.br/texto.pdf $\rangle$. Acesso em: 17 jul. 2016.

DAMATTA, Roberto. Você tem cultura? Rio de Janeiro: Revista da Embratel, 1981.

DEWEY, J. Experiência e Educação. Petrópolis/RJ: Ed. Vozes, 2010.

FREIRE, Paulo. Pedagogia da Autonomia: Saberes necessários à prática educativa. 29.ed. São Paulo: Paz e Terra, 2004.

HALL, Stuart (ed.). Introduction. In: Representation: cultural representations and signifying practices. London: Sage Publications, 1997.
IPHAN. Educação Patrimonial: Manual de aplicação: Programa Mais Educação / Instituto do Patrimônio Histórico e Artístico Nacional. Brasília, DF: Iphan/DAF/Cogedip/Ceduc, 2013.

IMC - INSTITUTO DOS MUSEUS E DA CONSERVAÇÃO. Kit de Recolha do Patrimônio Imaterial. Maio, 2011. Disponível em: <http://www.matrizpci.dgpc.pt/matrizpci.web/Down load/Kit/KIT\%20Recolha\%20Patrim\%C3\%B3nio\% 20imaterial_Integral.pdf>. Acesso em: 12 jul. 2016.

KONDER, Leandro. Walter Benjamin: O marxismo da melancolia. Rio de Janeiro: Civilização Brasileira, 1999.

KRAMER, Sonia. Infância, cultura contemporânea e educação contra a barbárie. In: Seminário Internacional Organização Mundial para a Educação Pré-escolar. Infância - Educação Infantil: reflexões para o início do século. Rio de Janeiro: Ravil, 2000.

VIGOTSKI, Lev. Imaginação $e$ criação na infância: ensaio psicológico: livro para professores. São Paulo: Ática, 2009.

\section{Sobre as autoras}

Cristina Carvalho é Doutora em Educação (PUC-Rio), Professora do Programa de Pós-Graduação em Educação da PUC-Rio, Coordenadora do Curso de Graduação em Pedagogia e do Curso de Especialização em Educação Infantil (PUC-Rio). Coordena o Grupo de Pesquisa em Educação, Museu, Cultura e Infância (GEPEMCI).

Maria Emília Tagliari Santos é Mestre em Educação (PUC-Rio), graduou-se em Comunicação Social - Cinema pela Universidade Federal Fluminense (2010). Integra o Grupo de Estudo e Pesquisa em Educação, Museu, Cultura e Infância (GEPEMCI/ PUC-Rio). Tem experiência nas áreas de Artes, Cinema e Educação não formal, atuando desde 2011 como educadora em instituições de arte.

Priscila Matos Resinentti é Doutora em Educação (PUC-Rio), Mestre em Educação (PUC-Rio), graduada em Licenciatura - Ciências Biológicas (UFRJ), Pós-Graduada em Educação Básica (UERJ), Membro do Grupo de Pesquisa em Educação, Museu, Cultura e Infância (GEPEMCI) e Professora da Rede Municipal de Educação do Rio de Janeiro e da rede privada.

Rosana Ferreira Alexandre é Doutora em Design (PUC-Rio), Mestre em Arte e Design para o Espaço Público (Universidade do Porto), graduada em Desenho Industrial/ Programação Visual (UFRJ) e Membro do Grupo de Pesquisa em Educação, Museu, Cultura e Infância (GEPEMCI).

Thamiris Bastos Lopes é Doutoranda em Educação (PUC-Rio), Mestre em Ciências da Museologia e do Patrimônio (UNIRIO), Graduada em Pedagogia (UERJ) e Membro do Grupo de Pesquisa em Educação, Museu, Cultura e Infância (GEPEMCI). 
Educação infantil e patrimônio cultural: diálogo entre educadores do Rio de Janeiro e de São Tomé e Príncipe

Recebido em abril de 2017

Aprovado em novembro de 2017 